a drug intravenously in a small volume to patients on maintenance haemodialysis, for not only are these patients heparinized during haemodialysis but many are also on long-term continuous warfarin therapy, and there is a very real danger of large haematomata forming after intramuscular injections.

Cephaloridine has been used widely in the maintenance haemodialysis unit at Fulham Hospital and side-effects have been limited to the occurrence of a sensitivity rash in one patient. The possibility of nephrotoxic side-effects is not important in these patients.
We are grateful to Mr. A. J. Pinegar, Glaxo Research Ltd., who carried out the microbiological assays, and to Sister J. M. Storey and the nursing staff of the maintenance haemodialysis unit, Fulham Hospital, who assisted in the collection of blood samples.

$$
\text { REFERENCES }
$$

Kabins, S. A., and Cohen, S. (1965). Antimicrobial Agents and Chemotherapy, 5, 922

Kunin, C. M., and Atuk, N. (1966). New England fournal of Medicine, 274,654 .

Naumann, P. (1967). Postgraduate Medical fournal, 43, August Suppl.,

pryor, J. S., Joekes, A. M., and Foord, R. D. (1967). Postgraduate Medical fournal, 43, August Suppl., p.82.

\title{
Burning-feet Syndrome. Case Due to Malabsorption and Responding to Riboflavine
}

\author{
C. S. LAI, ${ }^{*}$ M.B., M.R.C.P., M.R.C.P.ED.; G. A. RANSOME, † P.J.G., C.B.E., A.M., M.D., F.R.C.P.
}

\begin{abstract}
ummary: A woman with the burning-feet syndrome $\checkmark$ was found on investigation to have malabsorption. The syndrome responded rapidly to intramuscular injections of $6 \mathrm{mg}$. of riboflavine daily. It is suggested that deficiency of this substance, due to malabsorption and aggravated by a defective diet and repeated pregnancies, was responsible for the syndrome in this case.
\end{abstract}

\section{Introduction}

Burning pain in the feet was known to occur as a result of nutritional deficiency in tropical countries (Stannus, 1912; Landor and Pallister, 1935) and was a common disorder during the Spanish Civil War (Peraita, 1946) and in Japanese prisoner-of-war camps in the Far East during the second world war (Cruickshank, 1946; Smith and Woodruff, 1951). Most patients in these reports had coexisting clinical features suggestive of riboflavine and other vitamin deficiency, and they improved after being treated with yeast, rice polishings, or Marmite. The aetiology of the burning-feet syndrome, however, remained obscure, the deficient factor having been variously attributed to riboflavine (Landor and Pallister, 1935; Peraita, 1946), pantothenic acid (Gopalan, 1946), and nicotinic acid (Cruickshank, 1946). With the general improvement in nutrition after the second world war the syndrome became a rarity. It has become increasingly known, however, that malabsorption from various diseases of the gastrointestinal tract may be associated with neurological abnormalities. Cooke and Smith (1966) reviewed previous reports of neurological disorders associated with sprue and described another 16 cases of adult coeliac neuropathy. Fung and Khoo (1969) reported peripheral neuropathy in about $40 \%$ of cases of tropical sprue. In none of these was the burning-feet syndrome the predominant neurological complication. The following case of burning-feet syndrome in a woman with malabsorption responded dramatically to parenteral riboflavine therapy.

\section{Case Report}

A 21-year-old Indian housewife complained of pain in the soles of her feet of two weeks' duration. This was gradual in onset but was progressively getting worse. The pain was severe and burning "like fire", being persistent throughout the day and night but much worse during the night. She was unable to stand or walk, and suffered from insomnia. She had consulted a doctor at a maternity clinic and was told that she was "short of vitamins"; however, two oral multivitamin tablets three times daily given for two weeks did

\footnotetext{
* Senior Registrar in Medicine, Medical Unit 1, Outram Road General Hospital, Singapore 3.

† Professor of Medicine, Department of Medicine, University of Singapore, Singapore 3.
}

not relieve her burning pain. Each of these tablets contained thiamine $3 \mathrm{mg}$., riboflavine $1.5 \mathrm{mg}$., pyridoxine $0.5 \mathrm{mg}$., nicotinamide $10 \mathrm{mg}$., and vitamin D 250 i.u.

Three months previously, during the last two weeks of her fifth pregnancy, she had pain in the soles. This pain was less severe and not burning. It subsided spontaneously after parturition. Her earlier pregnancies had not been associated with such pain in the feet.

Her appetite was good. She had not been vomiting and did not have diarrhoea. She never complained of soreness in the tongue. Dietary inquiry showed that, because of personal idiosyncrasies, she was not getting a fair share of a rather defective family diet. The daily family intake of riboflavine was only about half the recommended allowance.

She was distraught with pain. Neither glossitis nor angular stomatitis was present, and no impairment had occurred in her hearing. Her blood pressure was 120/70. Her feet appeared normal and there was no change in their temperature. The dorsalis pedis pulses were easily felt. Muscle power and co-ordination were normal but she was apprehensive about bearing weight on her feet. The soles, however, were not tender to pressure, and appreciation of all sensory modalities was normal. The knee jerks were brisk but the ankle jerks were normal. Both plantar responses were flexor.

The results of relevant laboratory investigations were a haemoglobin level of $10.3 \mathrm{~g} . / 100 \mathrm{ml}$; serum iron was $84 \mu \mathrm{g} . / 100 \mathrm{ml}$., serum vitamin $B_{12} 515 \mu \mathrm{g} . / \mathrm{ml}$, , and serum folic acid $1.4 \mathrm{ng} . / \mathrm{ml}$ The serum albumin was $3.4 \mathrm{~g} . / 100 \mathrm{ml}$. and globulin $3.6 \mathrm{~g} . / 100 \mathrm{ml}$; serum calcium $8.8 \mathrm{mg} . / 100 \mathrm{ml}$. and serum pyruvate $0.3 \mathrm{mg} . / 100 \mathrm{ml}$ The sternal marrow showed increased cellularity, with moderate normoblastic hyperplasia; no megaloblasts were seen. The xylose excretion test with a $25-\mathrm{g}$. xylose load revealed a five-hour urinary excretion of only $0.7 \mathrm{~g}$. of xylose; a flat curve was obtained from the glucose tolerance test. Five hours after an oral dose of 350,000 i.u. of vitamin $A$ the rise in her serum vitamin $A$ level was only 340 i.u. $/ 100 \mathrm{ml}$. serum, the normal being at least 500 i.u./ $100 \mathrm{ml}$. Jejunal biopsy showed partial villus atrophy. The jejunum and ileum, however, appeared normal in barium small-bowel studies.

The diagnosis was burning-feet syndrome with malabsorption. She was given an ordinary hospital diet but liver was excluded. Analgesics did not relieve her pain, while spraying her soles with ethylchloride was equally ineffective. She was then given intramuscular injections of riboflavine $6 \mathrm{mg}$. daily. Within three days the burning pain had subsided to such an extent that she was anxious to be discharged from hospital, and by the sixth day of parenteral riboflavine therapy she was completely free from pain and walking about normally. Oral folic acid $5 \mathrm{mg}$. three times daily was subsequently given in addition.

\section{Discussion}

The burning-feet syndrome is rare in Singapore. It is curious that among the prisoners-of-war who had it nobody ever found out why it affected some and spared others. It seemed to pick out random cases as if there might be a partial inborn deficiency, perhaps in absorption, of the susceptible persons. 
The few cases seen by one of us (G.A.R.) were all Indians, and they took a long time to respond to vitamin- $B_{12}$ injections, vitamin-B complex injections, pantothenic acid, and diet. Unfortunately, the composition of the vitamin-B complex injections which had been used more than 10 years ago could not be determined. We therefore tried the effect of pure parenteral riboflavine in this case.

This was a classical case of a pure burning-feet syndrome. The patient had severe burning pains in the feet, worse at night, and apart from brisk knee jerks there was a significant absence of positive physical signs. She showed no clinical evidence of riboflavine deficiency. Though she did not suffer from diarrhoea, the low xylose excretion, the flat glucose tolerance curve, and the low vitamin-A-absorption test showed that she did in fact have malabsorption. Her defective diet and repeated pregnancies no doubt aggravated the situation.

This patient had very low serum folic acid levels, only 1.4 ng. $/ \mathrm{ml}$. Folate deficiency can give rise to various neurological disturbances (Brain, 1969), but it could not have been responsible for this patient's burning-feet syndrome, since this cleared up with parenteral riboflavine alone. Folic acid is absorbed from the jejunum and so is riboflavine (Selye, 1943). Riboflavine possesses vitamin activity only after it has been phosphorylated, a process thought to occur in the intestines. Riboflavine is not readily phosphorylated or absorbed in patients with gastrointestinal disease and is utilized only in such patients if it is injected (Bicknell and Prescott, 1953).

The burning-feet syndrome has long been recognized to be a result of vitamin deficiency, though the responsible factor has been controversial. Earlier observations noted the frequent association of the burning-feet syndrome with signs of riboflavine deficiency-corneal vascularization, angular stomatitis, glossitis, and scrotal dermatitis (Landor and Pallister, 1935; Stannus, 1944; Peraita, 1946). Hence it was thought that riboflavine was the deficient factor, and indeed the syndrome improved after treatment with substances containing riboflavine, such as yeast and Marmite. At that time a pure preparation of riboflavine was not available. Nevertheless, other workers reported little success in treatment of the burning-feet syndrome with riboflavine (Gopalan, 1946; Cruickshank, 1952). Cruickshank (1946), writing about his experience of 500 cases of the syndrome seen in prisoners-of-war in Singapore, thought the syndrome was due to deficiency of nicotinic acid, "perhaps in conjunction with riboflavine deficiency," after having found a good response in $68.8 \%$ of cases treated with intravenous diethylamide of nicotinic acid. During the later part of the war, however, there was no fresh outbreak of the burning-feet syndrome when the dietary content of nicotinic acid again fell to low levels. Pantothenic acid was later incriminated when Gopalan (1946) cured 53 cases by means of parenteral calcium pantothenate after having failed with thiamine, riboflavine, and nicotinic acid. Gopalan's results, however, could not be substantiated by Bibile et al. (1957) when they carried out a controlled therapeutic trial with pantothenol, the alcohol derivative of pantothenic acid.

The response of the present patient to intramuscular riboflavine therapy was dramatic. She obtained great relief of pain after three days and was completely cured after six days. During this period she was not given any other vitamin therapy, and liver was excluded from the ordinary hospital diet. In any case she suffered from malabsorption. While we cannot deny that the cure in this single case might have been a placebo response, it certainly draws attention back to the early hypotheses that riboflavine deficiency is the cause of the burning-feet syndrome.

We wish to thank Professor M. J. Colbourne, of the University Department of Social Medicine and Public Health, for carrying out the dietary investigations, and also Dr. W. P. Fung, of the Department of Clinical Medicine, for doing the jejunal biopsy.

\section{REFERENCES}

Bibile, S. W., Lionel, N. D. W., Dunuwille, R., and Perera, G. (1957). British fournal of Nutrition, 11, 434.

Bicknell, F., and Prescott, F. (1953). The Vitamins in Medicine, 3rd ed., p. 285. London, Heinemann.

Brain, M. C. (1969). In Recent Advances in Neurology and Neuropsychiatry, 8th ed., edited by Lord Brain and M. Wilkinson. London, Churchill.

Cooke, W. T., and Smith, W. T. (1966). Brain, 89, 683.

Cruickshank, E. K. (1946). Lancet, 2, 369.

Cruickshank, E. K. (1952). Vitamins and Hormones, 10, 1

Fung, W. P., and Khoo, O. T. (1969). Singapore Medical fournal, 10, 198.

Gopalan, C. (1946). Indian Medical Gazette, 81, 22.

Landor, J. V., and Pallister, R. A. (1935). Transactions of the Royal Society of Tropical Medicine and Hygiene, 29, 121.

Peraita, M. (1946). British Medical fournal, 2, 784.

Selye, H. (1943). Fournal of Nutrition, 25, 137

Smith, D. A., and Woodruff, M. F. A.' (1951). Medical Research Council. Special Report Series, No. 274.

Stannus, H. S. (1912). Transactions of the Society of Tropical Medicine and Hygiene, 5, 112.

Stannus, H. S. (1944). British Medical fournal, 2, 103.

\section{Preliminary Communications}

\section{Absence of Antidiuresis during Administration of Prostaglandin $\mathbf{F}_{2} \alpha$}

British Medical fournal, 1970, 2, 152-154

Qummary: Water diuresis was induced in six patients $\checkmark$ in mid-pregnancy. Three were then given oxytocin and the remainder prostaglandin $\mathbf{F}_{2} \alpha \quad\left(\mathbf{P G} \mathbf{F}_{2} \alpha\right)$, both drugs being infused intravenously in doses used to induce labour at term. Pronounced antidiuresis occurred with oxytocin, whereas $\mathbf{P G F}_{2} \alpha$ showed no such effect. The probable absence of any risk of water intoxication when using $\mathbf{P G F}_{2} \alpha$ in inducing labour may be of particular value when maternal pre-eclampsia or renal disease is present.

\section{INTRODUCTION}

Intravenous infusions of dilute solutions of oxytocin have been widely used for induction of labour. The success of the method is greatest when oxytocin is administered in the form of a titration (Turnbull and Anderson, 1968). Karim et al. (1969) successfully induced labour with prostaglandin $F_{2} \alpha$ $\left(\mathrm{PGF}_{2} \alpha\right)$, but if it is to be more widely used in the future $\mathrm{PGF}_{2} \alpha$ must be shown to carry advantages over oxytocin, which is of proved efficiency. One disadvantage of oxytocin is its antidiuretic action (Abdul-Karim and Assali 1961), which may lead to water intoxication (Liggins, 1962). This study shows that administration of $\mathrm{PGF}_{2} \alpha$ has no such complicating effect.

\section{METHODS}

Six patients admitted to hospital for termination of pregnancy by transabdominal intra-amniotic injection of hypertonic saline were studied. In all cases therapeutic abortion had been previously considered necessary on psychiatric grounds. The procedures and risks involved in the experiment were explained to the patients and their full consent and cooperation were obtained. None had any evidence of cardiac, renal, or other disease.

Water diuresis was induced in each by the intravenous 